\title{
Research on the Structural Evolution and Driving Mechanism of Regional Collaborative Innovation Network: Evidence from the Beijing-Tianjin-Hebei Urban Agglomeration
}

\author{
Xu Peipei ${ }^{1, *}$ Wang Ladi $^{1}$ \\ ${ }^{1}$ College of Management Science and Engineering, Shanxi University of Finance and Economics, Taiyuan, Shanxi \\ 030031, China \\ *Corresponding author. Email: pei_fighting@163.com
}

\begin{abstract}
The innovation network is an important support for regional integration development. Based on the co-patent dataset from Beijing-Tianjin-Hebei Urban Agglomeration, this paper portrays the structural characteristics and driving mechanism of the Beijing-Tianjin-Hebei collaborative innovation network by the method of social network analysis. Results show that: (1) Beijing-Tianjin-Hebei collaborative innovation network has developed from a sparse network to a complex network; Beijing has always been at the core of the network, and Tianjin and Shijiazhuang have gradually begun to play the role of network hubs, other cities have also actively participated in the collaborative development of innovation. (2) social proximity, institutional proximity, and organizational proximity play different roles in the formation of the innovation network. In addition, geographical proximity and economic proximity have not promoted the establishment of innovative links between cities.

Keywords: collaborative innovation network, structural evolution, driving mechanism, Beijing-Tianjin-Hebei Urban Agglomeration
\end{abstract}

\section{INTRODUCTION}

In the era of the knowledge economy, innovation is an endogenous driving force for regional economic development. Compared with urban innovation, which emphasizes the improvement of its innovation ability, regional innovation pays more attention to the construction of a collaborative innovation system between cities. The innovation network as an embodiment of the innovation links between cities is an effective way to explore the degree of regional innovation synergy, and it is also an important force to improve regional core competitiveness and promote regional coordinated development [1]. Beijing-Tianjin-Hebei urban agglomeration, as one of China's most dynamic and potential areas for economic development and technological innovation, still faces problems such as lack of innovative resource sharing mechanisms and incomplete long-term collaborative innovation mechanisms. Judging from the international experience of the innovative development of urban agglomerations, optimizing the innovation network structure of the urban agglomeration and achieving efficient internal linkages within the innovation network are the keys to building a world-class urban agglomeration. Therefore, it's necessary to explore the following questions: (1) What are the internal structural characteristics of the Beijing-Tianjin-Hebei Innovation
Network with the goal of regional collaborative innovation progress? And how did it evolve? (2) What factors should be adjusted in the future to make the Beijing-TianjinHebei collaborative innovation network structure and network relationship more optimized? Focusing on these issues, this paper constructs the Beijing-Tianjin-Hebei collaborative innovation network based on urban joint applications of invention patent data, reveals the structural characteristics evolution of the innovation network by the method of social network analysis, and explores the driving mechanism behind the formation of the innovation network.

\subsection{Related Work}

Freeman [2] put forward the concept of "innovation network" earlier, pointing out that the innovation network is a basic institutional agreement to deal with systemic innovation. The research on regional innovation networks with cities as nodes emphasizes the ability of cities to acquire external heterogeneous knowledge, it enhances knowledge creation capabilities through union and complementarity, and ultimately exerts a collaborative innovation effect [3].

The structural complexity of regional innovation networks has received extensive attention from many scholars. Scherngell et al. [4] explores the pattern of China's 
provincial knowledge innovation network using data of coauthored papers in 2007 mined from the CNKI database. Studies have generally found that regional innovation network has significant "core-edge" structure, and presents a spatial pattern of agglomeration and dispersion.

The driving mechanism behind the development of innovative networks has also received widespread attention. Abramovsky $\mathrm{L}$ et al. [5] proposes that geographical proximity is conducive to tacit knowledge exchange and promotes innovative cooperation. Besides, institutional proximity, cognitive proximity, and social proximity are also essential factors driving the growth of innovation networks [6].

\subsection{Our Contribution}

The contribution of our paper is twofold. First, time and space factors are integrated into the same framework to study the dynamic evolution of innovation networks. Second, multi-dimensional proximity is included in the analysis of the evolutionary mechanism of the innovation network to better explain the driving mechanism of the innovation network.

\subsection{Paper Structure}

The rest of the paper is organized as follows. Section2 introduces research methodology, which includes data collection, construction of innovation network and network analysis method. Section3 presents results and Section 4 concludes and discusses the limits of our analysis.

\section{DATA AND METHODOLOGY}

\subsection{Data Sources}

The joint application for invention patents reflects the interactive innovation process of knowledge flow and resource integration between regions. Therefore, this paper will use the joint application for invention patent data to build the Beijing-Tianjin-Hebei collaborative innovation network, the data comes from the patent search system of the State Intellectual Property Office (SIPO).

Considering that the period from application to publication of Chinese patents can be up to 18 months, to ensure data integrity and timeliness, and to describe the dynamic evolution of the innovation network, we chose to collect patent cooperation data for the three years of 2009, 2013 and 2017. Finally, with the city as the network node and the number of patent cooperation between cities as the side, the Beijing-Tianjin-Hebei collaborative innovation network was constructed.

\subsection{Social Network Analysis}

The Social Network Analysis method can quantitatively characterize the relationships in the network and reveal the network structure, which provides strong support for insight into the structural complexity of the BeijingTianjin-Hebei collaborative innovation network. Network structure analysis can start from two aspects: the entirety and node. For the overall network, indicators such as network size, network density, and average distance are commonly used to describe. For network nodes, the Centrality Analysis is usually used to evaluate the importance of the nodes in the network, that is, the position of each city in the Beijing-Tianjin-Hebei collaborative network.

\subsection{Multidimensional Proximity Framework}

Based on the proximity framework proposed by Boschma [7], this paper chooses geographical proximity, economic proximity, institutional proximity, social proximity, and organizational proximity to explores the influence of the attributes of urban relations on the Beijing-Tianjin-Hebei collaborative innovation network.

Geographical proximity refers to the geographical distance of cities in the innovation network. Use formula (1) to process geographical distance:

$$
\text { Geo }_{i j}=1-\ln \left(d_{i j}+1\right) / \ln \left(\operatorname{Max}\left(d_{i j}\right)+1\right)
$$

$d_{i j}$ is the spherical distance between city $\mathrm{i}$ and city $\mathrm{j}$ which calculated based on city's latitude and longitude.

Economic proximity is represented by the closeness of the level of urban economic development. We use the difference in per capita GDP to measure economic proximity and standardize it. The data comes from the CHINA CITY STATISTICAL YEARBOOK.

Institutional proximity refers to the degree of similarity between two cities' institutional environmental foundations. We take the gap in the level of administrative subordination of cities as the institutional distance between cities and use dummy variable method, assign the capital city a value of 3 , provincial capital cities and municipalities are assigned a value of 2 , and prefecturelevel cities are assigned a value of 1 .

Social proximity is generally associated with personal relationships social embeddedness between cities. We construct Jaccard index [8] to characterize the social proximity between two cities, as defined in equation (2).

$$
S o c_{i j}=I_{i j} /\left(C_{s}(i)+C_{s}(j)-I_{i j}\right)
$$

$I_{i j}$ indicates the number of innovation cooperation times for city i and city $\mathrm{j}, C_{s}(i)$ refers to the sum of the number of innovation cooperation times for city $i$ and all other cities in the Beijing-Tianjin-Hebei urban agglomeration. Organizational proximity refers to the membership to the same organizational entity that share similar norms, incentives and routines. Formula (3) is used to calculate organizational proximity. 


$$
\operatorname{Org}_{i j}=O_{i j} / \operatorname{Max}\left(O_{i j}\right)
$$

$O_{i j}$ refers to the number of institutions where the patentees of city $\mathrm{i}$ and city $\mathrm{j}$ carry out innovation cooperation belongs to the same organizational entity.

\section{RESULTS AND DISCUSSION}

\subsection{Structural Evolution}

This paper uses UCINET software to calculate a series of indicators that describe the overall structure of the network. The results are shown in Table 1.

Network size throughout the study period has always achieved full coverage of 13 cities in the Beijing-TianjinHebei region. Although the network size has stabilized, increasing network density indicates that the innovation network has evolved from a sparse network to a complex network. According to the value of the average distance, the overall smoothness of the network has significantly improved.

Table1 The overall structural characteristics of the innovation network

\begin{tabular}{|c|c|c|c|}
\hline Year & $\begin{array}{c}\text { Network } \\
\text { size }\end{array}$ & $\begin{array}{c}\text { Network } \\
\text { density }\end{array}$ & $\begin{array}{c}\text { Average } \\
\text { distance }\end{array}$ \\
\hline 2009 & 13 & 0.244 & 1.923 \\
\hline 2013 & 13 & 0.321 & 1.679 \\
\hline 2017 & 13 & 0.487 & 1.523 \\
\hline
\end{tabular}

The centrality analysis measures the position of each city in the Beijing-Tianjin-Hebei collaborative innovation network. To ensure the comparability of the centrality at different time points, the indicators listed in Table 2 are relative centrality indicators.

Table2 Centrality analysis of the innovation network

\begin{tabular}{|c|c|c|c|c|c|c|c|c|c|}
\hline & \multicolumn{3}{|c|}{ Degree centrality } & \multicolumn{3}{c|}{ Betweenness centrality } & \multicolumn{3}{c|}{ Closeness centrality } \\
\cline { 2 - 10 } & 2009 & 2013 & 2017 & 2009 & 2013 & 2017 & 2009 & 2013 & 2017 \\
\hline Beijing & 83.33 & 100.00 & 100.00 & 66.92 & 56.82 & 22.98 & 85.71 & 100.00 & 100.00 \\
\hline Tianjin & 41.67 & 58.33 & 100.00 & 4.80 & 6.82 & 22.98 & 63.16 & 70.59 & 100.00 \\
\hline Shijiazhuang & 50.00 & 75.00 & 83.33 & 20.71 & 16.67 & 10.99 & 66.67 & 80.00 & 85.71 \\
\hline Baoding & 33.33 & 25.00 & 50.00 & 16.67 & 0.00 & 1.77 & 60.00 & 57.14 & 66.67 \\
\hline Tangshan & 25.00 & 25.00 & 41.67 & 0.00 & 0.00 & 0.38 & 54.55 & 57.14 & 63.16 \\
\hline Cangzhou & 16.67 & 25.00 & 41.67 & 0.00 & 0.00 & 0.38 & 50.00 & 57.14 & 63.16 \\
\hline Handan & 16.67 & 25.00 & 25.00 & 0.00 & 0.00 & 0.00 & 52.17 & 57.14 & 57.14 \\
\hline Langfang & 8.33 & 8.33 & 41.67 & 0.00 & 0.00 & 0.00 & 48.00 & 52.17 & 63.16 \\
\hline Qinhuangdao & 8.33 & 16.67 & 33.33 & 0.00 & 0.00 & 0.00 & 48.00 & 54.55 & 60.00 \\
\hline Xingtai & 8.33 & 16.67 & 33.33 & 0.00 & 0.00 & 0.38 & 48.00 & 54.55 & 60.00 \\
\hline Zhangjiakou & 8.33 & 16.67 & 33.33 & 0.00 & 0.00 & 0.38 & 48.00 & 54.55 & 60.00 \\
\hline Hengshui & 8.33 & 16.67 & 33.33 & 0.00 & 0.00 & 0.00 & 38.71 & 54.55 & 60.00 \\
\hline Chengde & 8.33 & 8.33 & 16.67 & 0.00 & 0.00 & 0.00 & 41.38 & 52.17 & 54.55 \\
\hline Mean & 24.36 & 32.05 & 48.72 & 8.39 & 6.18 & 4.63 & 54.18 & 61.67 & 68.73 \\
\hline
\end{tabular}

The degree centrality of most cities has continued to increase during the research period, indicating that each city's participation in the innovation network has continued to increase. Beijing has always been at the center of the innovation network; Shijiazhuang and Tianjin occupy the second and third positions. From the perspective of the betweenness centrality, Beijing has the strongest control over the overall innovation network. In 2017, new cities began to play an intermediary role in the innovation network. The closeness centrality of all cities during the sample period continued to increase, the dependence of each node city on the core city of the network has continued to weaken and the independent innovation capability has constantly increased.

\subsection{Driving Mechanism}

The innovation network essentially reflects a binary matrix relationship, given that the Quadratic Assignment Procedure (QAP) of the social network analysis method can effectively solve the "relationship" problem between a single relationship matrix and multiple relationship matrices. Therefore, this article will introduce the QAP regression method. The driving mechanism measurement model of the innovation network is:

$$
\text { Inn }=f(G e o, \text { Eco, Ins, Soc, Org })
$$

In Formula (4), Inn is the innovation cooperation matrix of the Beijing-Tianjin-Hebei urban agglomeration, which is generated by the number of joint patent applications between two cities. Geo, Eco, Ins, Soc, and Org represent geographical proximity, economic proximity, institutional 
proximity, social proximity, and organizational proximity matrix, respectively. The regression results are presented in Table 3 .

Table3 QAP regression results of driving mechanism

\begin{tabular}{|c|l|l|l|c|c|c|c|}
\hline Year & Geo & Eco & Ins & Soc & Org & \# of obs. & R-squared \\
\hline 2009 & -0.049 & $-0.031 * *$ & $-0.014^{* *}$ & $0.909 * * *$ & $0.520 * * *$ & 156 & 0.235 \\
\hline 2013 & $-0.008^{*}$ & $-0.003 *$ & $-0.003 * *$ & $2.279 * * *$ & $0.023 * *$ & 156 & 0.299 \\
\hline 2017 & $-0.041^{* *}$ & $-0.008^{*}$ & $-0.005 * *$ & $2.548 * * *$ & $0.116^{* *}$ & 156 & 0.294 \\
\hline
\end{tabular}

Notes: *,**,***: significant at $10 \%, 5 \%, 1 \%$.

Geographical proximity indicates that geographical distance was not an obstacle to the formation of the innovation network. The possible reason is that the continuous development of information and communication technology and high-speed rail revolution reduces the "friction" effect of distance, and promotes effective communication of long-distance innovation cooperation.

Economic proximity had a significant negative impact on the construction of the innovative cooperation relationship. Although other low-income cities other than BeijingTianjin have high economic proximity, they cannot provide large $R \& D$ investments to maintain innovative cooperative relations.

The regression coefficient of institutional proximity was significantly negative. The institutional environment of cities at different administrative levels is quite different, and the endowment of innovation resources varies widely. The institutional barriers existing in the Beijing-TianjinHebei urban agglomeration hinder the flow of innovation resources to a certain extent.

Social proximity has always played a significant role in promoting urban innovation cooperation in different periods. This shows that the closer the social relations between cities, the more conducive to the development and deepening of innovation cooperation.

Organizational proximity has always played a positive role in the evolution of the Beijing-Tianjin-Hebei collaborative innovation network. The common rules, regulations, and values between the innovation subjects are conducive to the exchange of innovation knowledge.

\section{CONCLUSION}

This paper sheds light on the topic of how the structure of the Beijing-Tianjin-Hebei collaborative innovation network evolved and what factors affected the evolution of the innovation network. First, the Beijing-Tianjin-Hebei innovation network has a tendency to evolve from a sparse network to a complex network. The "one nuclear polarization" pattern has been shaken, the participation of other cities in the innovation network has also increased. Second, the formation and evolution of the BeijingTianjin-Hebei Innovation Network are the results of the combined effects of multidimensional proximity factors. Our findings call for policy measures specifically aiming at strengthening the construction of the Beijing-Tianjin-
Hebei collaborative innovation network. Firstly, The Beijing-Tianjin-Hebei urban agglomeration should be actively promoted to strengthen its innovative connection and form a closer, stable, and efficient innovation network. Secondly, in the matching of key elements, we must focus on the driving mechanism of the Beijing-Tianjin-Hebei innovation network. By building a Beijing-Tianjin-Hebei innovation resource sharing platform, deepening the cooperation mechanism of innovation subjects to improve social proximity; systematically promoting the integration and sharing of innovation incentive policies to reduce institutional barriers to innovation cooperation

\section{REFERENCES}

[1] R. Huggins, D. Prokop, Network structure and regional innovation: a study of university-industry ties, Urban Studies, vol.54, 2017, pp. 931-952. DOI: $10.1177 / 0042098016630521$

[2] C. Freeman, Networks of innovators: a synthesis of research issues, Research Policy, vol. 20, 1991, pp. 499-514, DOI: 10.1016/0048-7333(91)90072-X

[3] H. Ma, C. Fang, B. Pang, Structure of Chinese city network as driven by technological knowledge flows, Chinese Geographical Science, vol. 25,2015, pp. 498510, DOI: 10.1007/s11769-014-0731-0

[4] T. Scherngell, Y. Hu, Collaborative knowledge production in China: regional evidence from a gravity model approach, Regional Studies, vol.45, 2011, pp.755-772, DOI: 10.1080/00343401003713373

[5] L. Abramovsky, H. Simpson, Geographic Proximity and Firm-university Innovation Linkages: Evidence from Great Britain, Journal of Economic Geography, vol.11,2011, pp.949-977, DOI: 10.1093/jeg/lbq052

[6] G. Q. Lyu, G. Zeng, N. N. Gu, Literature review of regional innovation network: an economic geographical perspective, Economic Geography, vol.34,2014, pp.1-8, DOI: 10.15957/j.cnki.jjdl.2014.02.018 
[7] R. Boschma, Proximity and Innovation: A Critical Assessment, Regional Studies, vol.39, 2005, pp.61-74, DOI: $10.1080 / 0034340052000320887$

[8] C. L. Cheng, Q. C. Gui, D. Z. Duan et al., Structural heterogeneity and proximity mechanism of global scientific collaboration network based on co-authored papers, Acta Geographica Sinica, vol.72, 2017, pp.737752, DOI: 10.11821/dlxb201704014 